\title{
Bayesian structural equation modeling for examining the relationship between multidimensional factors and construction project cost
}

\author{
Linlin Zhao ${ }^{1}$, Zhansheng Liu ${ }^{1, *}$ and Jasper Mbachu ${ }^{2}$ \\ 1 Beijing University of Technology, Beijing, China; llzhao@bjut.edu.cn \\ 2 Bond University, Gold Coast, Australia; jmbachu76@outlook.com \\ * Correspondence: liuzhansheng83@sohu.com;
}

\begin{abstract}
Construction projects are usually operating in a complex and dynamic environment in which the accumulation of many interrelated factors causes high uncertainty. Construction projects are complex and frequently involve substantial uncertainties including process complicatedness, intricate organization structure, dynamic environment, and financial strain. The study aims to categorize the influencing factors into three groups, namely construction project system, economicmarket climate, and external environment. It attempts to adopt a novel analysis tool to examine the relationship between the project cost and multiple influencing factors by using Bayesian SEM. While the Bayesian SEM method has been receiving increasing attention in exploring the relationship between latent variables, construction studies still heavily rely on the covariance-based SEM approach. This study introduces several advantages of Bayesian SEM that make it more flexible and powerful than covariance-based SEM and provides the foundation of Bayesian SEM estimation and inference by illustrating this method in a project cost application.
\end{abstract}

Keywords: Construction project cost; influencing factors; Bayesian SEM; New Zealand

\section{Introduction}

Construction projects are usually operating in a complex and dynamic environment in which the accumulation of many interrelated factors causes high uncertainty. Their uniqueness and complicatedness means that they can be subject to massive unexpected events. The inherent complexities and uncertainties of construction projects are due to the involvement of many parties, as well as political, economic, and social conditions in which the projects are operating [1]. Previous studies and research mainly centered on investigating the impact effects of the influencing factors from one dimension or aspect on the triangle criterion of the projects in terms of cost, time, and quality [2]. The complicatedness and uncertainties might have negative effects on the project with respect to cost, time, quality, safety, and sustainability. Failure to adequately understand and manage them can result in cost overruns in construction projects [3]. It is impossible to avoid all the complications and uncertainties of any project.

The final project cost usually exceeds the original project cost because of the impact of uncertainty which is always difficult to predict and manage [4]. Uncertainties are caused by multiple factors; most of the time several influencing factors might occur simultaneously. Project cost management should be flexible enough to accommodate the changes to avoid project cost overruns. Establishment of a proper cost management strategy which tends to increase the probability of desired project cost performance is imperative. Indeed, a comprehensive assessment of cost drivers forms the foundation for developing realistic project cost management practices and strategies. Therefore, it is necessary to formulate a comprehensive and systematic examination of their impacts on the project, especially the project's cost. This process includes identifying, categorizing, and assessing the multiple influencing factors of construction project cost. 
Many studies and research have been conducted to state the influencing factors of project cost, and to suggest categories for them. However, the specific study concerning the case of New Zealand remains lacking. During last decade, construction projects in New Zealand experienced many events, such as an immigration wave, rapid economic development, the housing boom, and construction industry growth and expansion. Hence, massive efforts should be made to identify and manage the important influencing factors resulting from the dynamic operating environment in the New Zealand construction industry during the last decade.

Some advanced statistical techniques have also been introduced in construction studies and research. Structural equation modeling has become one of the most popular analysis methods in construction research over the last decade [5]. This widespread application stems from the fact that it is not only capable of exploring the relationships between measurement variables and latent variables but also the complex relationships among latent variables. As latent variables are difficult to be directly observed, normal analysis techniques cannot be used for observation.

Basically, SEM comprises a measurement model which can explore the relationship between the latent constructs and corresponding measurement indicators, and a structural model that reveals the relationship between latent constructs. SEM usually represents a covariance-based SEM that depends on the covariance matrix of the observed data [6]. In most cases, this approach can produce reliable results, but it is unable to produce correct results when its assumptions cannot be met [7]. Importantly, the accuracy of the parameter estimates by a covariance-based SEM approach is based on large sample size. Thus, it would encounter serious difficulties when using small samples [8].

Therefore, this study is to introduce the Bayesian SEM. Despite the increasing popularity of the Bayesian SEM in some research fields, it has yet to be widely applied in construction research and studies. Apart from being robust in small samples, it can cope with the unobserved heterogeneity in the form of various random effects and provides a better approximation of the level of uncertainty [8]. Because of these advantages, it is surprising that the number of Bayesian SEM studies and research in construction are limited. The study attempts to introduce the power of the Bayesian SEM.

The rest of this paper is organized as follows. Section 2 presents the literature review. Section 3 presents the grouped influencing factors and the hypothesis. Section 4 introduces the research methodology used in this study. Section 5 presents data analysis. The results are discussed in Section 6. The conclusion is presented in the final section.

\section{Literature Review}

\subsection{Influencing Factors of Construction Project Cost}

According to [9], 55 factors were identified and seven were recognized as the most significant cost drivers, such as collaboration and communication among involved parties, competency of the project team, leading capability of clients, and the socio-economic environment. In [10], a questionnaire survey and interview were conducted on construction professionals and concluded with ten most important influencing factors for construction projects, such as policy changes, market volatility, and bureaucratic organization structure. In [11], the essential factors for projects were revealed in the USA including regulation or code changes, contract conditions, financial failure, inflation, and weather.

In [12], a questionnaire survey on the largest Kuwaiti contractors was performed and the findings indicated that financial failure, contractual conditions, resources availability, collaboration and competence of the project team, political uncertainties, inflation, permits and regulations, weather conditions and Acts of God were all significant factors. In [13], a questionnaire survey and case study were carried out on contractors in China and the results explored a variety of influencing factors, such as regulation requirements, a client's objectives, competition, global trade influences, inefficient administration, the expertise of the project team, weather conditions, resources supply, and inflation. 
In [14], interview surveys with project professionals were undertaken in India but conducted by Singapore-based companies. And the study suggested that project financing and cultural differences are the main issues for those construction projects. In [15], a questionnaire survey of construction professionals was performed in Australia and the results indicate that factors deemed to impact construction projects include excessive administration procedures and resources supply. In [16], a fuzzy AHP method on questionnaire data was performed and the results explored that resources supply, management cost, inflation, and complex organizational structures can significantly influence project cost. In [17], the findings addressed that the political factor is one of the most influencing factors for construction projects because it is always related to the economy and investments which severely impact the exchange rate which, in turn, has a significant effect on imported goods. As [18] pointed out, stakeholders' influences, regulatory requirements, external environment threats, and global influences impose increased pressures on project cost management.

\subsection{Brief Overview of Bayesian SEM}

In Bayesian SEM, the prior information, Bayes' theorem, and posterior are introduced to better describe the data distribution than asymptotic approximation was adopted because the finite-sample distribution of data is unknown. The prior information is indeed a distinguishing advantage which quantifies a prior uncertainty in the analysis. As well, the Bayesian SEM can incorporate the prior information in the estimation. As for the added information provided by the data, more accurate and reliable parameter estimates can be obtained. Moreover, the uncertainty from the stochastic nature of the data was also considered in Bayesian SEM. Combining the random effects and the prior information, Bayes' theorem transfers prior information into posterior. In addition, the Markov Chain Monte Carlo used in Bayesian SEM can perform unlimited iteration while the maximum likelihood estimation in covariance-based SEM can only set a maximum number of iterations, like 500. If the limit is exceeded, the maximum likelihood estimates fail to converge.

\section{Development of Variables and Hypotheses}

Grouping the influencing factors is an integrative part of factor identification; it tends to structure the diverse influencing factors affecting construction projects [15]. Current literature also suggested that by categorizing the influencing factors into groups, the project team can better control and manage project cost if they can appropriately approach them [19].

Based on the findings of [20], the influencing factor of construction project cost can be grouped into project-related, client, industry and environment. In [10], influencing factors can be categorized into technical, management, financial, market, legal, and political factors in accordance with the nature of them. According to [21], the influencing factors of project cost can be grouped into project planning and control, market, technical, financial and regulatory categories. In the research conducted by [22], the influencing factors for project cost were classified into three groups, namely parent, management and resource factors. In [23], based on the nature of the influencing factors, they can be classified into physical, design, financial, political, legal, logistics, construction, environment and operation factors. Moreover, according to [24], they can also be categorized into internal and external factors. Internal influencing factors consist of design, construction, personal and operational, financial and contractual factors, while external influencing factors comprise political, socio, economic and environmental risks. Additionally, in [17], internal influencing factors including technical factors, non-technical factors, and legal factors are under the control of the project team, and external influencing factors, such as resources factors and financial factors, are beyond the control of the project team. According to the existing literature and the opinions of the experts, the important cost drivers were identified and assessed. They are divided into three main categories: construction project system, economic-market climate, and external environment. 
The conduct of construction projects contains various challenges which may stem from the conflicts from different involved parties and poor coordination and collaboration [25]. Organizational structure and stability are also an important aspect for construction project execution [26]. Moreover, if a company has a clear understanding of the potential project risks and devises appropriate management strategies accordingly, a successful project is achievable [27, 28]. Based on the findings of $[29,30]$, the project professionals should be equipped with experienced and competent members as they will improve the project's productivity which in turn influences project performance. Additionally, the resource supply and management is also a key determinant for a successful project as the shortage of required resources would delay the project which in turn could lead to conflicts and attrition among the involved parties [31,32]. The selection of contractual form and statements in the contract documents can decide the payment methods, a spread of risks, and disputes resolution methods. Contractual conditions which suggest the risk allocation and payment methods have a significant effect on the project cost as either improper risk transfers or delayed payments can lead to conflicts among the stakeholders which, in turn, affects project performance [33, 34].

\subsection{Economic Market Climate}

To examine project success opportunity and risk, devise management practices and strategies, and formulate a business plan, market analysis is imperative [35]. Addressing market conditions, market components like competition and economic trends should be examined properly [36]. Moreover, the economic market climate should include market volatility, fluctuations in inflation and interest rates, and exchange rates [37]. Economic stability can significantly influence the construction industry through employment and investments [38,39]. Moreover, these factors also impose great challenges on clients' and construction companies' behavior. For example, a reduced demand increases the competition between companies in the construction industry. As the construction industry usually relies on various financial approaches to meet its capital needs, inherent financial constraints impose further influences on the overall project cost [40].

\subsection{External Environment}

According to [41], global influences pose challenges to project cost performance, but industry professionals are less familiar with them. Political stability and financial influences play an important role in the broader economy in which construction projects operate; and they are usually considered as external influencing factors due to their being beyond the control of the stakeholders [42-44]. The construction industry is substantially affected by economic conditions [45]. It is important to understand that the global economy shapes many national economic activities. Furthermore, natural disasters also present many risks in a project's operational environment.

\subsection{Hypotheses}

While the definition of project cost could be different from one organization to another, the most reliable and reasonable project cost definition lies in three dimensions. There are capital construction cost, associated capital cost, and client-related cost [46]. Using the categories of the influencing factors and dimensions of project cost, a hypothetical diagram of the research model is shown in Figure 1. The corresponding hypotheses are as follows:

- Hypothesis 1: Construction project system (CPS) has a significant effect on the construction project cost (CPC) in New Zealand.

- Hypothesis 2: Economic-market climate (EMC) has a significant effect on the construction project cost (CPC) in New Zealand.

- Hypothesis 3: External environment (EE) has a significant effect on the construction project cost (CPC) in New Zealand. 
- Hypothesis 4: Economic-market climate (EMC) significantly influences construction project system (CPS).

- Hypothesis 5: External environment (EE) significantly influences economic-market climate (EMC).

- Hypothesis 6: External environment (EE) significantly influences construction project system (CPS).

As [47] addressed, the category of the influencing factors is regarded to be highly subjective, refinement of the right sort of measurement indicators for the true representation of the latent constructs is a complex task. One observed variable is difficult to represent or measure the latent construct. A comprehensive list of measurement indicators that clearly represent the corresponding latent constructs was developed, as shown in Table 1.

Table 1. Latent constructs and corresponding measurement indicators

\begin{tabular}{clc}
\hline Constructs & \multicolumn{1}{c}{ Factors } & Sources \\
\hline & Resource supply and management (CPS1) & {$[31,32]$} \\
Construction & Competence and experience of key professionals (CPS2) & {$[29,30]$} \\
Project System & Relationship management and network development (CPS3) & {$[25]$} \\
(CPS) & Organizational structure (CPS4) & {$[26]$} \\
& Risk management (CPS5) & {$[27,28]$} \\
& Contractual conditions (CPS6) & {$[33,34]$} \\
\hline & Market structure and size (EMC1) & {$[48,49]$} \\
& Competition level (EMC2) & {$[36]$} \\
Economic- & Economic stability (EMC3) & {$[38,39]$} \\
Market & Investment management (EMC4) & {$[50]$} \\
Climate (EMC) & Inflation target and interest management (EMC5) & {$[37]$} \\
& Credit supply conditions (EMC6) & {$[40,51]$} \\
& Exchange rate fluctuation (EMC7) & {$[52]$} \\
\hline \multirow{2}{*}{ External } & Political stability (EE1) & {$[42-44]$} \\
Environment & Financial integration and deepening (EE2) & {$[53-55]$} \\
(EE) & Global economic climate (EE3) & {$[45]$} \\
& Natural disasters (EE4) & {$[56,57]$} \\
\hline Construction & Capital construction cost (CPC1) & \\
Project cost & Associated capital cost (CPC2) & {$[46]$} \\
(CPC) & Client-related cost (CPC3) & \\
\hline
\end{tabular}




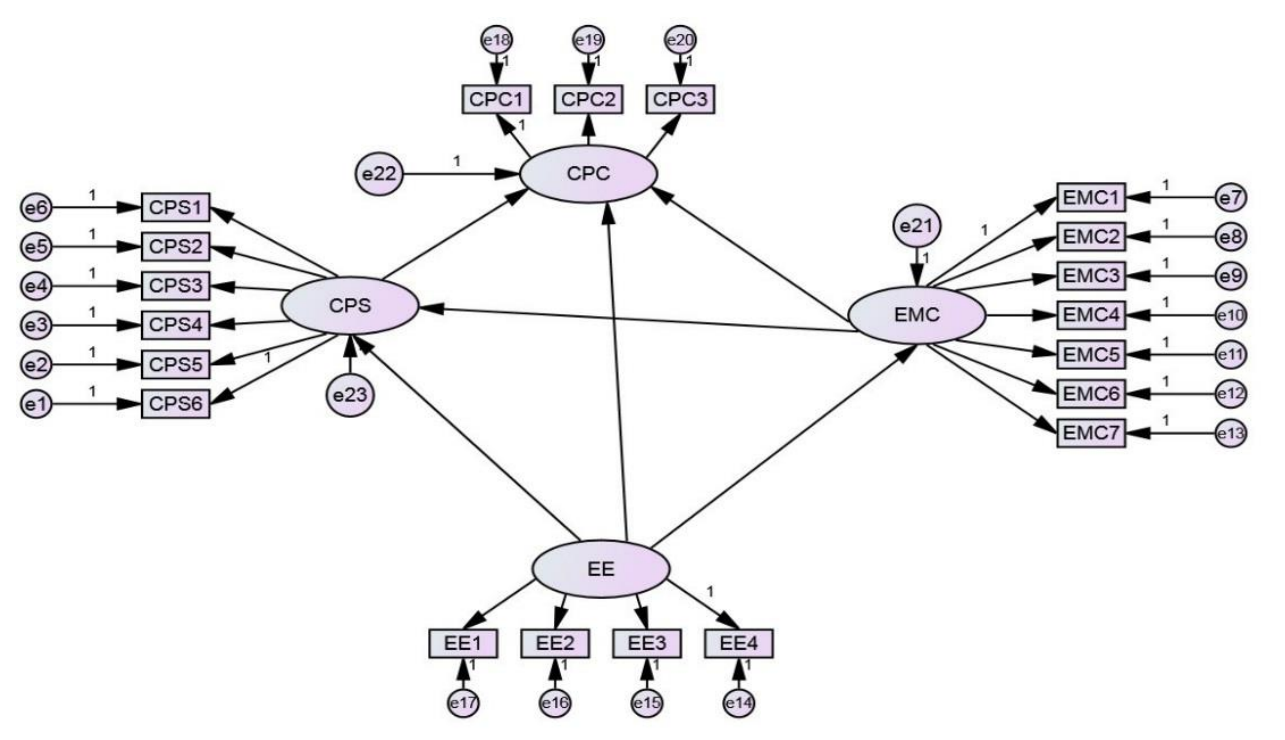

Figure 1. The proposed research model

\section{Research Methodology}

The research methods adopted in this study are threefold: literature review, a pilot survey, and a questionnaire survey. A draft questionnaire survey was developed, consisting of four parts. The first part - a covering letter - contains the research aims and objectives. The second part is the main questionnaire which requests the respondents to rate the influencing level of the measurement indicators by using a five-point Likert-scale ( $1=$ very weak, $2=$ weak, $3=$ =medium, $4=$ strong, $5=$ =very strong). A five-point response format is desirable because it is sensitive to differentiating the responses and it satisfies the reliability and validity requirements [58]. The third part is a demographic section which requests background data of the respondents. The final part is the request form for respondents to request a copy of the research findings.

Prior to formal distribution of the questionnaire survey, a pilot survey was carried out; 12 experts including three academicians and nine experienced industry practitioners assessed and evaluated the components of the questionnaire. Some questions were refined, rephrased and reworded for better understanding. The target population for this study are registered members of the Association of Consulting Engineers of New Zealand (ACENZ), New Zealand Institution of Architects (NZIA), and New Zealand Institute of Quantity Surveyors (NZIQS). The professional backgrounds of the respondents comprise working experience, profession, and occupation.

\subsection{Questionnaire Response}

The questionnaire was published on Survey Monkey to generate a web-link and then the potential respondents were informed by sending the web-link to their email address. This distribution means to improve the response quality, speed up the response cycle, and minimize research cost [59]. Of the 329 questionnaires that were distributed, 78 were completed and were considered to be useful. Hence, the response rate for the questionnaire was 23.7 percent. This response rate is reasonable based on previous similar studies and research [22, 60]. Of the respondents, 13 percent have 6-10 years' working experience, 31 percent have 11-15 years' working experience, 27 percent have 16-20 years' working experience, 19 percent have 21-25 years' working experience, and 10 percent have more than 25-years' working experience. Of the 78 responding practitioners, 20 are architects, 18 are structural engineers, 12 are service engineers, 26 are quantity 
surveyors, and two are project managers. The background information of the respondents is shown in Table 2.

Table 2. A summary of respondents' profiles

\begin{tabular}{cccccc}
\hline Profession & No. & Experience & Percent (\%) & Organization & Percent (\%) \\
\hline Architect & 20 & $6-10$ & 13 & Consultancy & 52 \\
Structural Engineer & 18 & $11-15$ & 31 & Contractors & 10 \\
Service Engineer & 12 & $16-20$ & 27 & Construction & 33 \\
Quantity Surveyor & 26 & $21-25$ & 19 & Other & 5 \\
Project Manager & 2 & $>25$ & 10 & & \\
\hline
\end{tabular}

\subsection{Basic Concepts of Bayesian SEM}

To reveal the relationship between latent constructs is essential, particularly for complex problems. One analysis approach that is usually adopted to examine the relationship between the latent variables is structural equation modeling - SEM. One important requirement in this method is that the sample size must be large enough. According to [61], the sample size is appropriately 100200. The parameter estimates in SEM depend on matrix variance covariance that is heavily based on the asymptotic normality of the sample. A small sample in SEM using a common method such as Maximum Likelihood Estimation (ML) or Generalized Least Squares (GLS) can produce a negative variance and singular covariance matrix, and then generating biased parameter estimates [62]. SEM has a limited ability to account for cross-loading and residual correlation as they are fixed to zero, while Bayesian SEM can resolve these issues [63]. Measurement indicators are seldom perfectly pure construct indicators. Even a completely reliable rating of the indicator of the construct is likely to have a significant association with multiple constructs.

Although pure indicators only for one construct might exist, most indicators present some level of association with other constructs [64]. The exclusion of cross-loading in an analysis would cause inflated construct correlations [65]. This point is also confirmed by [64] where it is addressed that construct correlations appear to be upwardly biased if the cross-loadings are constrained to be zero. Even when the small and meaningless cross-loadings are ignored in the model, the construct correlations tend to be substantially biased. Moreover, Bayesian SEM can identify the residual correlation that is the main reason to cause the misfit of the SEM model and inaccuracy of the parameter estimates [66]. Sometimes the misfit in the SEM model might be due to the ignorance of the residual correlations rather than a major difference between the model and data.

Based on the above mentioned, an alternative approach is necessary. Bayesian SEM tends to allow that the model development can be performed even if some essential assumptions are not fulfilled. Unlike the SEM method relying on variance covariance matrix, Bayesian SEM depends on the number of observations [67]. In SEM, the estimated parameter is not considered as a random variable, while in Bayesian SEM it is considered as a random variable that has a distribution referred to as prior distribution.

\section{Data Analysis}

SEM, a multivariate analysis technique, was used to test the proposed research model in this study. The following reasons make it a promising tool in the research field. First, SEM is widely accepted as a reliable approach to hypothesis testing [68]. Second, as a multivariate analysis, it is allowed to analyze multiple relationships simultaneously [69]. Finally, it is able to examine the causal relationship between latent variables [61]. Moreover, Bayesian SEM was adopted in this study, instead of the common Maximum Likelihood Estimation and Generalized Least Squares (GLS) in covariance-based SEM. 


\subsection{Bayesian SEM}

The proposed research model would be examined by using Bayesian SEM. In Bayesian SEM, all estimated coefficients are reported in terms of posterior distribution. Parameters significance testing can be conducted by using 95 percent confidence interval which is the lower limit percentiles of 2.5 percent and the upper limit percentiles of 97.5 percent of the posterior distribution [70]. The significance of a parameter depends on whether or not a zero value lies in a confidence interval [67]. If a confidence interval does not contain a zero value, the parameter is significant. Otherwise, if the zero value is included in the confidence interval, the parameter is not significant or has no effects on the dependent variable.

The parameter significance testing can be carried out on both the measurement model and the structural model. In the measurement model, a significant indicator means it is acceptable to measure the corresponding latent construct. In the structural model, the parameter significance testing can determine whether there is significant influence between the latent constructs. The regression weights and the associated 95 percent confidence intervals between the measurement indicators and corresponding latent constructs and between the latent constructs are shown in Table 3 and Table 4, respectively. From the results presented in Table 3, the factor loadings are all significant at the 5 percent level, except the indicator exchange rate fluctuation (EMC7). While, from the results of the structural model as shown in Table 4, it is known that of the six parameters tested, four parameters were recognized as significant. It can be concluded that Hypotheses 1, 2, 4, and 5 were supported, while Hypotheses 3 and 6 were not supported.

Hypothesis 3, stating that external environment has a significant effect on construction project cost, is not supported by the regression weight of EE on CPC with a confidence interval from -0.174 to 2.031. The relevant regression weight for Hypothesis 6, i.e., the external environment has a significant effect on construction project system, has a posterior confidence interval between -0.195 to 0.409 . Therefore, both hypotheses were not supported.

For Hypothesis 1, which addressed that construction project system has a significant effect on construction project cost, the confidence interval for the regression parameter is from 0.675 to 0.986 , significantly larger than zero. Hypothesis 2, which asserted that economic-market climate has a significant effect on construction project cost, has a confidence interval between 0.670 and 0.925 , a parameter significantly greater than zero. Support was found for Hypothesis 4 , stating that economicmarket climate can significantly affect construction project system, with the confidence interval range from 0.001 to 0.206 . Finally, Hypothesis 5 was supported, which said that external environment has a significant effect on economic-market climate, with a confidence interval between 0.328 and 0.779 . So, these four hypotheses are supported. 
Table 3. Bayesian SEM measurement model results

\begin{tabular}{|c|c|c|c|c|}
\hline Path & Mean & SD & $\begin{array}{c}95 \% \text { Lower } \\
\text { bond }\end{array}$ & $\begin{array}{c}95 \% \text { Upper } \\
\text { bond }\end{array}$ \\
\hline CPS1 & 0.933 & 0.061 & 0.820 & 1.062 \\
\hline $\mathrm{CPS} 2-\mathrm{CPS}$ & 0.927 & 0.065 & 0.805 & 1.058 \\
\hline CPS3-CPS & 0.914 & 0.064 & 0.795 & 1.044 \\
\hline CPS4-CPS & 1.033 & 0.064 & 0.913 & 1.164 \\
\hline CPS5 - & 1.035 & 0.065 & 0.916 & 1.169 \\
\hline EMCZ-EMC & 0.983 & 0.057 & 0.876 & 1.100 \\
\hline EMC3־EMC & 0.991 & 0.053 & 0.890 & 1.101 \\
\hline EMC——EMC & 0.989 & 0.054 & 0.887 & 1.099 \\
\hline EMC5-EMC & 0.979 & 0.056 & 0.874 & 1.094 \\
\hline EMC & 0.985 & 0.058 & 0.877 & 1.104 \\
\hline EMCЖーEMC & -0.17 & 0.084 & -0.338 & -0.008 \\
\hline EE1ヶ EE & 0.987 & 0.090 & 0.823 & 1.174 \\
\hline $\mathrm{EE} 2 \longleftarrow \mathrm{EE}$ & 1.030 & 0.090 & 0.865 & 1.219 \\
\hline EE3ヶ EE & 1.036 & 0.094 & 0.864 & 1.229 \\
\hline $\mathrm{CPC} 2 \longleftarrow \mathrm{CPC}$ & 0.933 & 0.106 & 0.740 & 1.153 \\
\hline СРС $3 \longleftarrow$ СРС & 0.919 & 0.102 & 0.731 & 1.134 \\
\hline
\end{tabular}

Table 4. Bayesian SEM results of hypotheses testing

\begin{tabular}{|c|c|c|c|c|c|}
\hline Hypotheses & Path & Mean & SD & $\begin{array}{l}95 \% \text { Lower } \\
\text { bond }\end{array}$ & $\begin{array}{c}95 \% \text { Upper } \\
\text { bond }\end{array}$ \\
\hline H1 & $\mathrm{CPC} \longleftarrow \mathrm{CPS}$ & 0.819 & 0.079 & 0.675 & 0.986 \\
\hline $\mathrm{H} 2$ & $\mathrm{CPG}-\mathrm{EMC}$ & 0.792 & 0.065 & 0.67 & 0.925 \\
\hline H3 & $\mathrm{CPC} \longleftarrow \mathrm{EE}$ & 0.797 & 0.569 & -0.174 & 2.031 \\
\hline $\mathrm{H} 4$ & $\mathrm{CPS} \longleftarrow \mathrm{EMC}$ & 0.102 & 0.052 & 0.001 & 0.206 \\
\hline H5 & $\mathrm{EMC} \longleftarrow \mathrm{EE}$ & 0.583 & 0.075 & 0.328 & 0.779 \\
\hline $\mathrm{H} 6$ & $\mathrm{CPS} \longleftarrow \mathrm{EE}$ & 0.097 & 0.153 & -0.195 & 0.409 \\
\hline
\end{tabular}

\subsection{Model Assessment}

Poster predictive $p$-value is used to assess the research model as it can account for both the fit between the research model and the observed data and the match between the replicated data and the observed data [71, 72]. The poster predictive close to a value of 0.5 indicates a good fit. In this study, the posterior predictive p-value is 0.46 , indicating the model fits the data well.

Although Bayesian SEM has advantages over covariance-based SEM, convergence problems would bias the result of Bayesian estimation [73]. So, a convergence check should be conducted in Bayesian SEM in order to obtain the adequate model. However, the convergence checking is not a simple task in Markov Chain Monte Carlo (MCMC) estimation as it is devised to converge in distribution rather than to a point estimate [74]. A single convergence test is not enough; it is common to graphically inspect several varying aspects of convergence conditions including time series plot and posterior density plots [75, 76]. Typically, a parameter appears to converge when a tight horizontal band is formed from sample estimations in a posterior trace plot. Otherwise, if a trace plot shows substantial fluctuation, it is most likely the parameter has not reached convergence.

The convergence trace plot as shown in Figure 2 has a tight band that lies within two parallel horizontal lines; no trend is shown that indicates the parameters converge properly. As shown in trace plots in Figure 2, after several thousands of iterations, the sequences of the values generated at different starting points have mixed well. 
Moreover, if a polygon formed a bell-shape in approximately normal density in posterior distribution, the parameter is properly converged [71]. A smoothed density for the posterior distribution of the variance of construction project cost is shown in Figure 3. The estimated value of the variance is 0.520 , which is close to 0.5 . According to [77], the estimated variance value of 0.5 indicates a perfect model fit, either too smaller or too greater than 0.5 indicates a bad fit. This indicates that the variance of construction project cost is well accounted for by the proposed model. The remaining variables' variances are similar to that in Figure 3 and indicate the variances are well accounted for by the model.

\subsection{Model Comparison}

It is very common in SEM to compare a set of competing models and select the best-fit one. Although Bayesian Information Criterion (BIC) is derived from Bayesian theory, it is frequently used for model comparison in covariance-based SEM [78]. Bayes factor is another good statistic that can be used for model comparing, but it is sensitive to prior inputs [79]. Therefore, a notion of Bayesian deviance, Deviance Information Criterion (DIC), was introduced for model comparison in Bayesian SEM by [72]. Similar to the BIC, the model that has the smallest DIC from a set of comparing models is favorable. From previous results, the final model deletes the insignificant paths of the first model. The DIC results indicate the final model has a better fit than the first model, as shown in Table 5. The final model is shown in Figure 4.
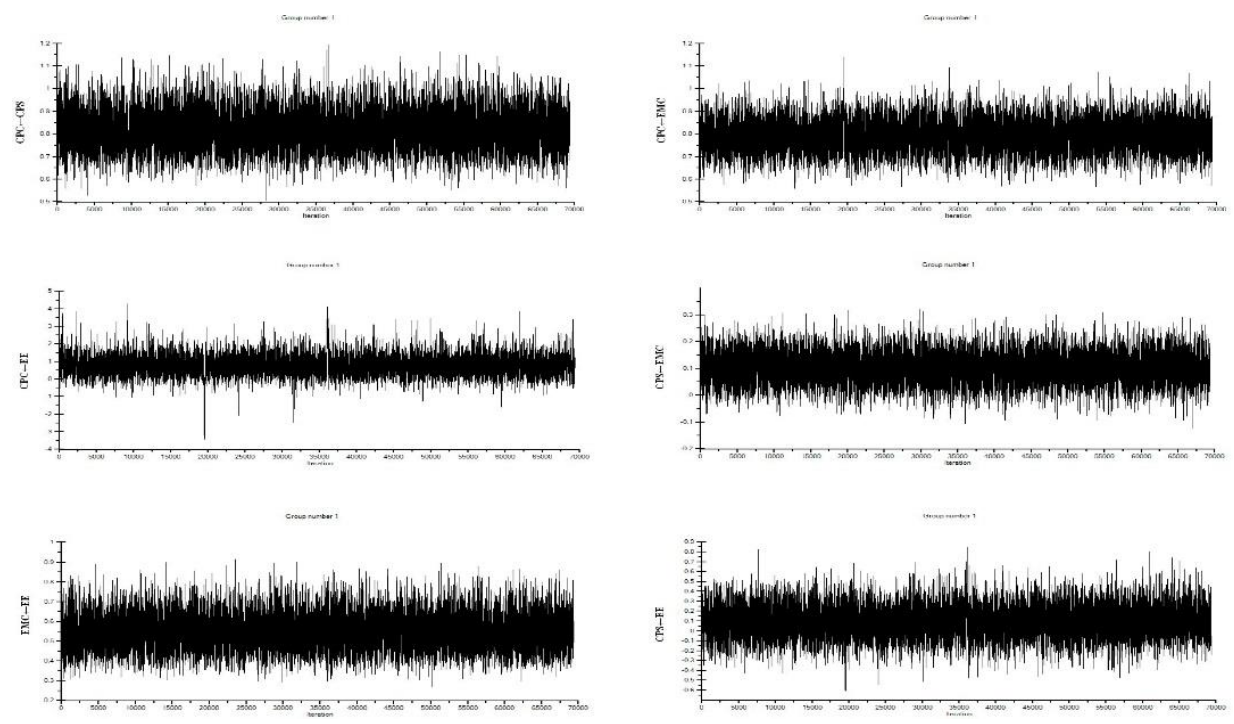

Figure 2. Trace plot convergence for model parameters 


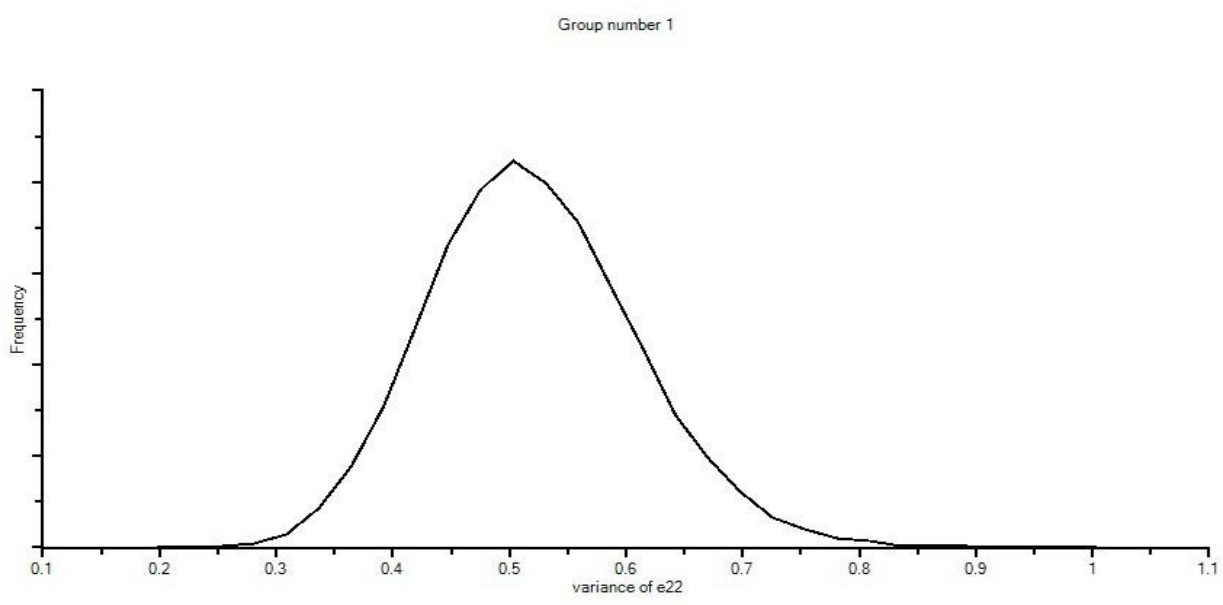

Figure 3. Posterior density of the model residue

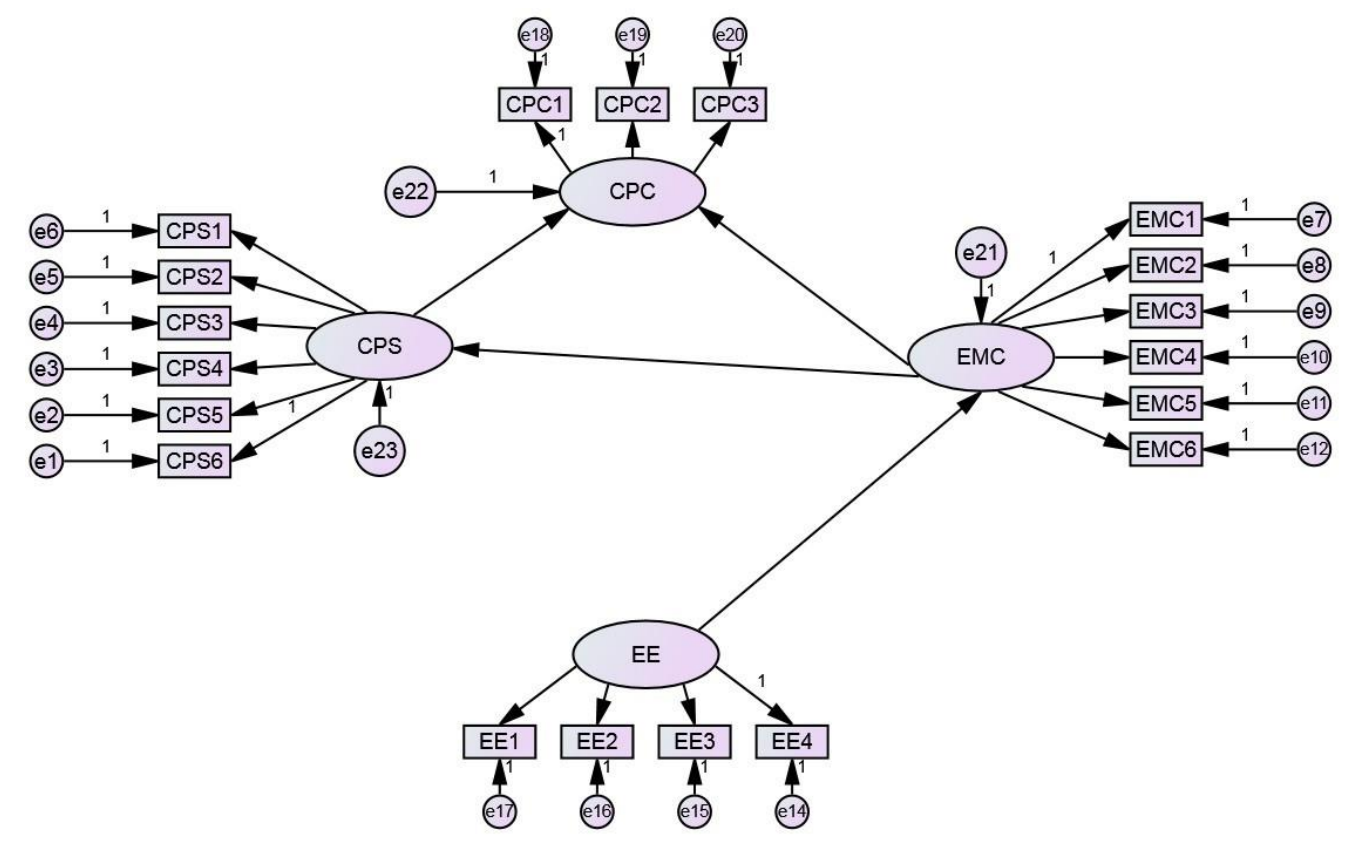

Figure 4. The final research model

Table 5. Model fit comparison

\begin{tabular}{ccc}
\hline Model & Posterior p-value & DIC \\
\hline First model & 0.46 & 470.4 \\
Final model & 0.48 & 466.6 \\
\hline
\end{tabular}




\section{Results Discussion}

The objectives of this study are to empirically test the effects of construction project system, economic-market climate and external environment on project cost of construction project. Moreover, the mediate and moderate effects of external environment on construction project cost through economic market climate and construction project system have also been investigated. Additionally, the examination about whether construction project system is bounded by economic market climate has also been undertaken. Research hypotheses are grounded in existing research findings and empirical results and tested by Bayesian SEM.

A first important and empirical finding in this study is that construction project system has a significant direct effect on construction project cost. It also supports the previous study related to project cost management [80, 81]. Moreover, the significant direct effect of economic market climate on construction project cost has also been confirmed. In essence, this finding can be explained that because the construction project needs a huge amount of working capital to run the daily construction activities, capital is one of its most important factors. As most contractors rely heavily on their financial sources, the conditions of the credit supply can significantly affect their financial abilities. This explanation is also consistent with previous research conducted by [82, 83]. Another important finding relates to the significant effect of economic market climate on construction project system, upholding preceding research findings $[84,85]$. Based on this finding, the study suggests that to better manage project cost, the construction professionals should facilitate appropriate practices and strategies in respect of resource management and risk management. Additionally, the postulated relationship between external environment and economic-market climate was also substantiated. A possible explanation for this finding in this respect is that the natural disaster incorporated into external economic construct was considered as one of the main reasons driving up the demand for construction products as the sudden demand posed a raft of challenges to construction resources.

However, the significant direct effect of external environment on construction project cost has not been confirmed. This result contradicts previous research findings [86] which addressed that project operation environment has a significant effect on project success. In our opinion, this result may be caused by the data employed. As the data were collected from consultants such as architects, engineers, and quantity surveyors, they might be more concerned with tangible factors like construction resource rather than intangible factors like global business sentiments. Furthermore, the significant direct effect of external environment on construction project system was not supported in this study. This result goes against the previous research finding [87]. The reason is that with respect to project success or project performance, this study only considers project cost as a criterion of project success. However, in light of the complexity of construction project, project success or performance goes beyond project cost management, by representing technology innovation and quality improvement [88]. In this respect, the explanation can be that some questionnaire respondents have been involved in construction projects where risk reduction or quality improvement is relatively more important than project cost management.

\section{Conclusion}

Although many research and studies have been conducted on construction project cost, the influencing factors of project cost vary considerably across countries. Moreover, few studies have been undertaken on modeling the cost using Bayesian SEM, particularly when information on construction project system, economic-market climate, and external environment are considered. This paper also explored that construction project system and economic-market climate can significantly affect the construction project cost, but external environment cannot. Moreover, an economic-market climate can significantly influence a construction project system. However, the external environment has a significant direct effect on economic-market climate.

The identification of important influencing factors provides information to key stakeholders from inception to completion of the construction project. It provides a knowledge base that supports the management of cost and improves cost management by detecting gaps during the examination. 
The findings would contribute to both research and industry in cost management for the New Zealand construction industry and would also provide useful information for foreign firms which intend to develop construction projects in New Zealand. This paper provided a comprehensive introduction to the Bayesian technique for structural equation modeling. Although receiving increasing attention across other research fields, the application of the Bayesian SEM is still highly limited in the construction literature. The study highlighted the merits of the Bayesian SEM and illustrated its distinctiveness from the traditional covariance-based SEM approach.

Overall, there are three reasons why construction researchers might select Bayesian SEM over covariance-based SEM. First, as addressed several times previously, the Bayesian SEM is able to accommodate small samples. Second, based on proper identification of prior information and Markov Chain Monte Carlo simulation, the Bayesian technique can generate more accurate parameter estimation. Third, the Bayesian SEM can provide more accurate and less sensitive fit measures.

Despite the power of the Bayesian SEM, naïve application of it should not be encouraged. According to [89], without a good understanding of the approach, the application can be dangerous, especially in terms of interpreting the Bayesian features and outputs. Moreover, the selection of appropriate priors is also an empirical issue in Bayesian SEM. From here, performing comparison analysis to check the results across different prior choices could be a further research area. 
Author Contributions: Conceptualization, J.M. and Z.L.; methodology, J.M.; software, L.Z.; validation, J.M.; resources, Z.L.; writing-original draft preparation, L.Z.; writing-review and editing, Z.L.; project administration, J.M.; funding acquisition, L.Z.

Funding: This research was funded by China Scholarship Council, grant number 201206130069, Massey University, grant number 09166424 . The APC is funded by the both grants.

Acknowledgments: The authors would like to thank the China Scholarship Council (CSC) for its support through the research project and the Massey University. The authors would like to thank Association of Consulting Engineers of New Zealand (ACENZ), New Zealand Institution of Architects (NZIA), and New Zealand Institute of Quantity Surveyors (NZIQS) for providing data to conduct this research. In addition, I would like to thank all practitioners who contribute in this project.

Conflicts of Interest: The authors declare no conflict of interest.

\section{References}

1. El-Sayegh, S. M., Risk assessment and allocation in the UAE construction industry. International Journal of Project Management 2008, 26 (4), 431-438.

2. Tam, C. M.; Zeng, S. X.; Deng, Z. M., Identifying elements of poor construction safety management in China. Safety Science 2004, 42 (7), 569-586.

3. Andi, The importance and allocation of risks in Indonesian construction projects. Construction Management and Economics 2006, 24 (1), 69-80.

4. El-Karim, S. A.; Nawawy, O. A.; Abdel-Alim, A. M., Identification and assessment of risk factors affecting construction projects. Housing and Building National Research Center 2017, 13, 202-216.

5. Fellows, R.; Liu, A., Research methods for construction. Wiley-Blackwell: Oxford, 2008.

6. Lee, S.-Y.; Song, X.-Y., Bayesian structural equation model. WIRES: Computational Statistics 2014, 6 (4), 276287.

7. Assaf, A. G.; Oh, H.; Tsionas, M. G., Unobserved heterogeneity in hospitality and tourism research. Journal of Travel Research 2016, 55 (6), 774-788.

8. Rossi, P. E.; Allenby, G. M., Bayesian statistics and marketing. Marketing Science 2003, 22 (3), 304-328.

9. Iyer, K. C.; Jha, K. N., Factors affecting cost performance: Evidence from Indian construction projects. International Journal of Project Management 2004, 23, 283-295.

10. Shen, L. Y.; Wu, G. W. C.; Ng, C. S. K., Risk assessment for construction joint ventures in China. Journal of Construction Engineering and Management 2001, 127 (1), 76-81.

11. Kangari, R., Risk management perceptions and trends of US construction. Journal of Construction Engineering and Management 1995, 1 (4), 422-439.

12. Kartam, N.; Kartam, S., Risk and its management in the Kuwaiti construction industry: a contractors' perspective. International Journal of Project Management 2001, 19 (6), 325-335.

13. Fang, D. P.; Li, M. G.; Fong, S.-W.; Shen, L. Y., Risks in Chinese construction market - contractors' perspective. Journal of Construction Engineering and Management 2004, 130 (6), 853-861.

14. Ling, F.; Hoi, L., Risks faced by Singapore firms when undertaking construction projects in India. International Journal of Project Management 2006, 24, 261-270.

15. Zou, X. W.; Zhang, G.; Wang, J.-Y., Identifying key risks in construction projects: Life cycle and stakeholder perspectives. International Journal of Construction Management 2014, 9 (1), 1-14.

16. Taylan, O.; Bafail, A.; Abdulaal, M. S.; Kabli, M. R., Construction projects selection and risk assessment by fuzzy AHP and fuzzy TOPSIS methodologies. Applied Soft Computing 2014, 17 (6), 105-116. 
17. Khodeir, L. M.; Mohamed, A. H. M., Identifying the latest risk probabilities affecting construction projects in Egypt according to political and economic variables. Housing and Building National Research Centre Journal 2015, 11 (1), 129-135.

18. KPMG Singapore risk management survey: trends, benefits and challenges of the risk management experience in Singapore; KPMG: Singapore, 2006.

19. Qian, S., Rethinking the implementation of project management: A Value Adding Path Map approach. International Journal of Project Management 2011, 29 (3), 295-302.

20. Chapman, R. J., The controlling influences on effective risk identification and assessment for construction design management. International Journal of Project Management 2001, 19 (3), 147-160.

21. Liu, J. Y.; Zou, X. W.; Gong, W., Managing project risk at the enterprise level: exploratory case studies in China. Journal of Construction Engineering and Management 2013, 139 (9), 1268-1274.

22. Chen, P.; Wang, J., Application of a fuzzy AHP method to risk assessment of international construction projects. In International Conference on Electronic Commerce and Business Intelligence, Beijing, China, 2009.

23. Akintoye, A. S.; Macleod, M. J., Risk analysis and management in construction. International Journal of Project Management 1997, 15 (1), 31-38.

24. Thuyet, N. V.; Ogunlana, S. O., Risk management in oil and gas construction projects in Vietnam. International Journal of Energy Secret Management 2007, 1 (2), 175-180.

25. Huang, S.-M.; Chang, I.-C.; Li, S.-H.; Lin, M.-T., Assessing risk in ERP projects: identify and prioritize the factors. Industrial Management and Data Systems 2004, 104 (8), 681-688.

26. Bharat, M.; Kumar, V.; Kumar, U., Delineating the ERP institutionalization process: go live to effectiveness. Business Process Management Journal 2010, 16 (4), 744-771.

27. Aloini, D.; Dulmin, R.; Minionno, V., Risk management in ERP project introduction: Review of the literature. Information $\mathcal{E}$ Management 2007, 44 (6), 547-567.

28. Lim, S. H.; Koh, C. E., RFID implementation strategy: perceived risks and organizational fits. Industrial Management and Data Systems 2009, 109 (8), 1017-1036.

29. Biazzo, S., Process mapping techniques and organizational analysis: lessons from socio technical system theory. Business Process Management Journal 2002, 8 (1), 42-52.

30. Okrent, M. D.; Vokurka, R. J., Process mapping in successful ERP implementations. Industrial Management and Data Systems 2004, 104 (8), 637-643.

31. Garg, P.; Garg, A., Factors influencing ERP implementation in retail sector: an empirical study from India. Journal of Enterprise Information Management 2014, 27 (4), 424-448.

32. Gargeya, V. B.; Brady, C., Success and failure factors of adopting SAP in ERP system implementation. Business Process Management Journal 2005, 11 (5), 501-516.

33. Baloi, D.; Price, A. D. F., Evaluation of global risk factors affecting cost performance in Mozambique. In COBRA Conference, 2001.

34. Nasir, D.; McCabe, B.; Hartono, L., Evaluating risk in construction-schedule model (ERIC-S): Construction schedule risk model. Journal of Construction Engineering and Management 2003, 129 (5), 518-527.

35. Karaveg, C.; Thawesaengskulthai, N.; Chandrachai, A., A combined technique using SEM and TOPSIS for the commercialization capability of R\&D project evaluation. Decision Science Letters 2015, 4, 379-396.

36. Frederick, H. H.; Kuratko, D. F., Entrepreneurship. $2^{\text {nd }}$ ed.; Asia-Pacific Edition: Sydney, 2010.

37. Zhang, X., Financial viability analysis and capital structure optimization in privatized public infrastructure projects. Journal of Construction Engineering and Management 2005, 131 (6), 656-668.

38. Kirikkaleli, D., Interlinkage between economic, financial, and political risks in the Balkan countries: Evidence from a panel cointegration. Eastern European Economics 2016, 54 (3), 208-227. 
39. Torabi, R.; Eshraghi, M.; Nagheli, E., Financial stability and economic performance in OPEC countries: An approach to co-integration methods. International Journal of Management, Accounting E Economics 2017, 4 (1), 56-65.

40. Cheng, Y.-M., An exploration into cost-influencing factors on construction projects. International Journal of Project Management 2014, 32, 850-860.

41. Baloi, D.; Price, A. D. F., Modeling global risk factors affecting construction cost performance. International Journal of Project Management 2003, 21 (4), 261-269.

42. Ashley, D.; Bonner, J., Political risks in international construction. Journal of Construction Engineering and Management 1987, 113 (3), 447-467.

43. Kangari, R.; Lucas, C. L., Managing international operations: A guide for engineers, architects and construction managers. . ASCE Press: US, 1997.

44. Rosenbaum, D. B., Questions hamper deals. Engineering News Record 1997, 24 (11).

45. Lavingia, N. J., Improve profitability through effective project management and TCM. Cost Engineering 2003, 45 (11), 22-24.

46. ICMS Global consistency in presenting construction costs; International Construction Measurement Standards.: London, UK, 2017.

47. Aikin, L. S.; Stein, J. A.; Bentler, P. M., Structural equation analysis of clinical sub-population differences and comparative treatment outcomes: characterizing the daily lives of drug addicts. Journal of Consulting and Clinical Psychology 1994, 62, 488-499.

48. Ball, M.; Farshchi, M.; Grilli, M., Competition and the persistence of profits in the UK construction industry. Journal of Construction Management and Economics 2000, 18 (733-745).

49. Chiang, Y.-H.; Tang, B.-S.; Leung, W.-Y., Market structure of the construction industry in Hong Kong. Construction Management and Economics 2001, 19, 675-687.

50. Disatnik, D.; Steinhart, Y., Need for cognitive closure, risk aversion, uncertainty changes, and their effects on investment decisions. Journal of Marketing Research 2015, 52 (3), 349-359.

51. Arnold, M.; Wagner, A. F.; Westermann, R., Growth options, macroeconomic conditions, and the cross section of credit risk. Journal of Financial Economics 2013, 107, 350-385.

52. Yildirim, Z., \& Ivrendi, M. (2016). Exchange rate fluctuations and macroeconomic performance. Journal of Economic Studies, 43(5), 678-698., Exchange rate fluctuations and macroeconomic performance. Journal of Economic Studies 2016, 43 (5), 678-698.

53. Aizenman, J.; Pinto, B.; Sushko, V., Financial sector ups and downs and the real sector in the open economy: up by the stairs, down by the parachute. Emerging Markets Review 2013, 16, 1-30.

54. Mirdala, R., Financial integration and financial deepening in the selected European transition economies. Journal of Applied Economic Sciences 2008, 4 (6), 419-433.

55. Trabelsi, M.; Cherif, M., Capital account liberalization and financial deepening: Does the private sector matter? Quarterly Review of Economics and Finance 2017, 64, 141-151.

56. Benson, C.; Clay, E.; Michael, F. V.; Robertson, A. W. Dominica : natural disasters and economic development in a small island state The World Bank: Washington, D.C., 2001.

57. Sisk, B.; Bankston-III, C. L., Hurricane Katrina, a construction boom, and a new labor force: Latino immigrants and the New Orleans construction industry, 2000 and 2006-2010. Population Research and Policy Review 2013, 33 (3), 309-334.

58. Marsden, P. V.; Wright, J. D., Handbook of survey research. Emerald Group Publishing Ltd: UK, 2010.

59. Klassen, R. D.; Jacobs, J., Experimental comparison of web, electronic and mail survey technologies in operations management. Journal of Operations Management 2001, 19, 713-728. 
60. Xiong, B.; Skitmore, M.; Xia, B.; Masrom, M. A.; Ye, K.; Bridge, A., Examining the influence of participant performance factors on contractor satisfaction: A Structural Equation Model. International Journal of Project Management 2014, 32, 482-491.

61. Hair, J. F.; Black, W. C.; Babin, B. J.; Anderson, R. E., Multivariate data analysis. Pearson Education International: New Jersey, 2010.

62. Kogan, L., Small-sample inference and bootstrap. MIT, Sloan: US, 2010.

63. Muthen, B.; Asparouhov, T., Bayesian SEM: A more flexible representation of substantive theory. Psychological Methods 2012, 17, 313-335.

64. Marsh, H. W.; Morin, A. J.; Parker, P. D.; Kaur, G., Exploratory Structural Equation Modeling: An integration of the best features of exploratory and confirmatory factor analysis. Annual Review of Clinical Psychology 2014, 10, 85-110.

65. Stromeyer, W. R.; Miller, J. W.; Sriramachandramurthy, R.; DeMartino, R., The prowess and pitfalls of Bayesian Structural Equation Modeling: important considerations for management research. Journal of Management 2015, 41, 491-520.

66. Asparouhov, T.; Muthen, B.; Morin, A. J., Bayesian Structural Equation Modeling with cross-loadings and residual covariances: comments on Stromeyer et al. Journal of Management 2015, 41 (6), 1561-1577.

67. Sari, D. K.; Wardhani, N. W. S.; Astutik, S., Parameter estimation of Structural Equation Modeling using Bayesian approach. Journal of Pure and Applied Mathematics 2016, 4 (2), 86-94.

68. Lee, S.-Y.; Song, X.-Y.; Tang, N.-S., Bayesian methods for analyzing structural equation models with covariates, interaction, and quadratic latent variables. Structural Equation Modeling 2007, 14, 404-434.

69. Song, X.-Y.; Lee, S.-Y., A tutorial on the Bayesian approach for analyzing Structural Equation Models. Journal of Math and Psychology 2012, 56, 135-148.

70. Ntzoufras, I., Bayesian modeling in WinBugs. John Wiley \& Sons, Inc.: USA, 2009.

71. Gelman, A.; Rubin, D. B., Inference from iterative simulation using multiple sequences. Statistical Science 1992, 7, 457-511.

72. Spiegelhalter, D. J.; Best, N. G.; Carlin, B. P.; van de Linde, A., Bayesian measures of model complexity and fit. Journal of the Royal Statistical Society 2002, 64, 583-639.

73. Holtmann, J.; Koch, T.; Lochner, K.; Eid, M., A Comparison of ML, WLSMV, and Bayesian methods for multilevel Structural Equation Models in small samples: A simulation study. Multivariate Behavioral Research 2016, 51 (5), 661-680.

74. Sinharay, S., Experiences with Markov Chain Monte Carlo convergence assessment in two psychometric examples. Journal of Educational and Behavioral Statistics 2004, 29, 461-488.

75. Bernardo, J. M.; Berger, J. O.; Dawid, A. P.; Smith, A. F. M., Bayesian statistics. Oxford University Press: UK, 1992.

76. Gilks, W. R.; Richardson, S.; Spiegelhalter, D. J., Markov Chain Monte Carlo in practice. Chapman \& Hall: New York, 1996.

77. Levy, R., Bayesian data-model fit assessment for Structural Equation Modeling. Structural Equation Modeling: A Multidisciplinary Journal 2011, 18 (4), 663-685.

78. Hoyle, R. H., Structural Equation Modeling: concepts, issues, and applications. Sage: Thousand Oaks, CA, 1995.

79. Kass, R. E.; Raftery, A. E., Bayes factors. Journal of the American Statistical Association 1995, 90, 773-795.

80. Chua, D. K. H., Critical success factors for different project objectives. Journal of Construction Engineering and Management 1999, 125 (3), 142-150. 
81. Lowe, D. J.; Emsley, M. W.; Harding, A., Relationships between total construction cost and project strategic, site related and building definition variables. Journal of Financial Management of Property and Construction 2006, 11 (3), 165-180.

82. Krishnamurthy, P., Banking deregulation, local credit supply, and small-business growth. Journal of Law and Economics 2015, 58 (4), 935-967.

83. Wachter, S. M., Credit supply and housing prices in national and local markets. Public Finance Review 2016, $44(1), 6-21$.

84. Shenhar, A. J., One size does not fit all projects: exploring classical contingency domains. Management Science 2001, 47, 394-414.

85. Shenhar, A. J.; Dvir, D., Reinventing project management: The diamond approach to successful growth $\mathcal{E}$ innovation. Harvard Business School Press: Watertown, MA, 2007.

86. Priemus, H.; Flyvbjerg, B.; Wee, B., Decision-making on Mega-projects: cost-benefit analysis, planning and innovation. Edward Elgar Publishing: UK, 2008.

87. Cooke-Davies, T.; Crawford, L.; Patton, J. R.; Stevens, C.; Williams, T. M. Aspects of complexity: managing projects in a complex world; Project Management Institute: Newtown Square, PA, 2011.

88. Mashwama, N.; Aigbavboa, C.; Thwala, D., An assessment of the critical success factor for the reduction of cost of poor quality in construction projects in Swaziland. Procedia Engineering 2017, 196, 447-453.

89. Depaoli, S.; van de Schoot, R., Improving transparency and replication in Bayesian statistics: The WAMBSChecklist. Psychol Methods 2017, 22 (2), 240-261. 